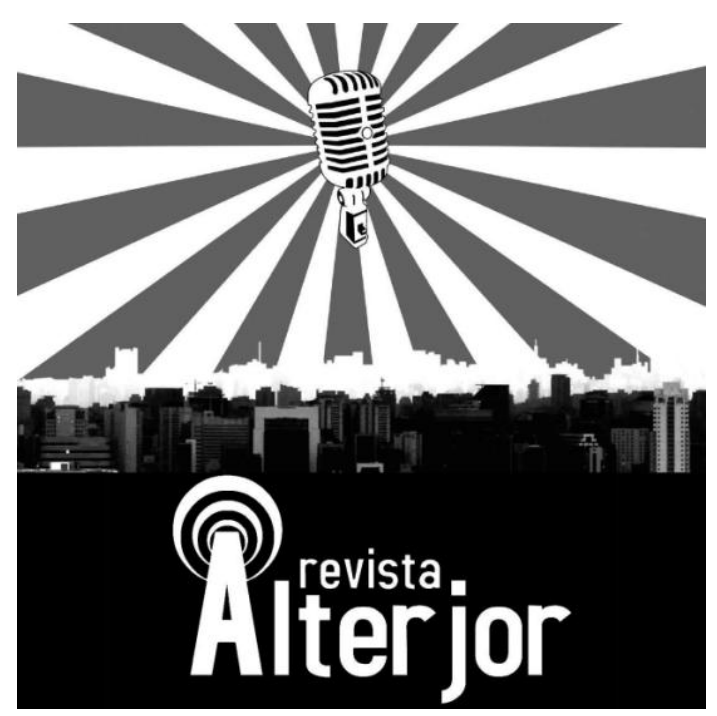

ENTREVISTA

\title{
KIA ORA BRAZIL: O RÁDIO MULTICULTURAL POR MAYA HASEGAWA
}

\author{
Carlos Augusto Tavares Junior ${ }^{1}$
}

RESUMO: Este artigo aborda a entrevista com a artista e radialista Maya Hasegawa ocorrida em 5 de novembro de 2020 durante a disciplina Diálogos Radiojornalísticos, do Programa de Pós-Graduação em Ciências da Comunicação da Universidade de São Paulo. Com base nas experiências relatadas, este trabalho tem a finalidade de mostrar como a intersecção cultural de uma imigrante brasileira no rádio comunitário da Nova Zelândia estabelece laços multiculturais e cria vínculos como uma ação efetiva para a promoção da diversidade cultural.

PALAVRAS-CHAVE: Maya Hasegawa. Kia Ora Brazil. Rádio. Nova Zelândia. Comunidade.

ABSTRACT: This article deals with an interview with the artist and radio host Maya Hasegawa, which took place on November, 5, 2020, during the academic discipline Radio Journalism Dialogues from Postgraduate Program in Communication Sciences at the University of São Paulo. Based on reported experiences, this article also has the purpose to show how the cultural intersection of a Brazilian immigrant in the New Zealand community radio set up multicultural bonds and creates links as an effective action to foster cultural diversity.

KEYWORDS: Maya Hasegawa. Kia Ora Brazil. Radio. New Zealand. Community.

\footnotetext{
1 Doutor em Ciências da Comunicação pela USP. Aluno de pós-doutorado do Departamento de Jornalismo e Editoração da Escola de Comunicações e Artes da Universidade de São Paulo. E-mail: carlostavaresjr@alumni.usp.br
}

\section{Revista ALTERJOR}

Grupo de Estudos Alterjor: Jornalismo Popular e Alternativo (ECA-USP)

Ano 12 - Volume 01 - Edição 25 - Janeiro-Junho de 2022

Av. Professor Lúcio Martins Rodrigues, 443, Cidade Universitária, São Paulo, CEP: 05508-020 


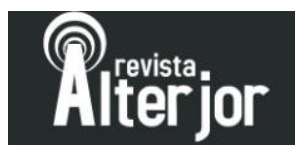

\section{Introdução}

Antes de imigrar com a família na Nova Zelândia, a descendente de japoneses Maya Hasegawa atuava na área de saúde formou-se no curso de Farmácia-Bioquímica pela Universidade de São Paulo (USP). Na Nova Zelândia além de adentrar em contato com uma atmosfera cultural, também passa a desenvolver projetos artísticos como atriz e cantora. Mas foi na Radio Free FM (89,0 MHz) de Hamilton que surgiu um trabalho capaz de catalisar a nova carreira de Hasegawa.

A entrevista ocorreu durante a realização da disciplina Diálogos Radiojornalísticos, do Programa de Pós-Graduação em Ciências da Comunicação (PPGCOM) da USP com utilização da infraestrutura de Tecnologia em Informação da mesma instituição, por meio da parceria com o provedor Google e o serviço Workspaces for Educational Fundamentals, proporcionou a realização da gravação do material e a comunicação em tempo real no ambiente de aula com 12 participantes, entre eles, o Professor Luciano Victor Barros Maluly, supervisor da pesquisa e os pós-doutorandos em 2020: Lourival Galvão Júnior e Pedro Serico Vaz Filho, que fizeram perguntas à entrevistada.

Em meio à primeira onda de contaminação da doença COVID19, antes do agravamento da contaminação pela cepa Gama (P1) em janeiro de 2021, a aula também foi realizada em ambiente remoto com alunos do PPGCOM. Também se enfatiza a diferença de fuso horário em 14 horas, resultando também no agendamento antecipado do evento: enquanto a aula ocorria numa tarde de quinta-feira no Brasil, Maya Hasegawa participou da mesma aula em uma manhã de sexta-feira.

O programa Kia Ora ${ }^{2}$ Brazil, transmitido em inglês, possui a típica formatação do talk show, com entrevistas a convidados, voltado ao segmento da prestação de serviços e utilidade. A cobertura em FM corresponde a uma região de área estimada em $120 \mathrm{~km}^{2}$. Neste momento fazem-se necessárias as ressalvas com relação à forma de gestão e funcionamento das rádios comunitárias na Nova Zelândia: a lei de radiodifusão (Communication Act) (1989, n. 5) em que se destaca o estabelecimento de uma Comissão de Radiodifusão para as seguintes atribuições, conforme o artigo 36 , parágrafo 1 , inciso 3 , linha 5 :

A principal função das Comissões são: [...] manter e ampliar a cobertura da transmissão radiofônica e televisiva às comunidades da Nova Zelândia que, de outra forma não receberiam um sinal

\footnotetext{
${ }^{2}$ Saudação no idioma maori. Equivale aos cumprimentos olá e tchau.

Revista ALTERJOR

Grupo de Estudos Alterjor: Jornalismo Popular e Alternativo (ECA-USP)

Ano 12 - Volume 01 - Edição 25 - Janeiro-Junho de 2022 Av. Professor Lúcio Martins Rodrigues, 443, Cidade Universitária, São Paulo, CEP: 05508-020
} 
comercialmente viável e [...] para garantir que um limite de transmissão esteja disponível para atender aos interesses de [...] minorias nas comunidades, incluindo minorias étnicas e estimular uma série de transmissões disponíveis para [...] encorajar o estabelecimento e operação de arquivos de programas de interesse histórico para a Nova Zelândia ${ }^{3}$.

Neste contexto, Maya Hasegawa explica como funcionam as emissoras comunitárias, como a Free FM, a captação de recursos e a estrutura do programa Kia Ora Brazil:

E aí em torno de rádio [...] vou falar do CAMA (Communitary Access Media Alliance) que se assemelha lá em sequer a associação digamos das rádios comunitárias são 12 rádios comunitárias na Nova Zelândia que captam recursos cada uma em torno de 135 a 250.000 dólares neozelandeses por ano através de Patrocínio normal assim temos apoio de uma churrascaria que brasileira que vai abrir, o Lions [Club] também patrocina e assim vai. São entidades diversas e o Kia Ora também conta com apoio parte governamental, que dá o recurso financeiro. [A emissora veicula programas] em torno de mais de 40 idiomas em toda essa programação e eles falam que o principal, o mote deles, é de cobrir temas e nichos que a grande mídia não tem interesse. Ou pelo menos eles acham que não tem a plataforma -é muito legal o conteúdo multimídia, se vocês puderem acessar um dia, eles trazem todas as rádios comunitárias ali você pode ouvir tanto ao vivo o quanto onde a mãe se você vai lá e procura biblioteca deles de todas as 12 rádios então como eu falei eles também tem um aplicativo que você pode ouvir como se fosse um podcast normal. Apesar de que, por exemplo, a rádio [Free FM] em que eu tenho meu programa eles também disponibilizam por isso para todas as outras formas convencionais, mas a gente tem uns aplicativos específicos.

Sobre o acesso à captação de recursos, Maya Hasegawa também aborda as exigências:

E só para você saber que não é assim: Oba vai ter a festa do Caqui, a gente tem umas revisões anuais que os principais digam acionistas ou responsáveis da rádio e em cada uma das rádios e fazem uma reunião conosco para mostrar os dados: senhora, quanto a gente investiu quanto vocês conseguiram captar de recurso? Qual é a variedade de programação e tudo mais que vocês estão apresentando com a qualidade? O que o público está dizendo de vocês? - Eles puxam nossa orelha ou nos dão um tapinha nas costas conforme a performance [audiência do programa]. Então não é uma coisa simplesmente assim de ir ao governo brasileiro para te dar um dinheiro.

\footnotetext{
3 Tradução nossa. Disponível em: https://www.legislation.govt.nz/act/public/1989/0025/latest/whole.html\#DLM158011
} 
Quanto à audiência, Maya Hasegawa também menciona uma mudança nos perfis de público:

As pessoas estavam meio que migrando, cansadas da TV comum e muita gente [que] está dirigindo ou cozinhando [também está] ouvindo seu podcast então o governo daqui falou assim beleza por isso que a rádio a gente vai incentivar e criar o podcast de ter essa planilha assim essa plataforma e aí eles estão acompanhando aqui os números, de como é que estão crescendo os podcasts. Eles todos estão muito maravilhosamente apresentados nos sites tanto do Cama quanto do Acess Radio. [Sobre] o gênero eles comparam também o quanto que cresce tudo isso e eles estão olhando aqui e sempre falam: olha as mulheres estão aumentando o número de produção. Mas queremos mais então eles bem sempre com aquela puxadinha de orelha nas rádios falando. Cadê? Queremos mais queremos mais tanto aqui nessa semana eu vou gravar uma campanha para as rádios tentando captar mais podcasters, mais pessoas que estejam interessadas em gravar, porque eles querem mais conteúdo.

Com relação á disponibilização de mais conteúdo para imigrantes brasileiros na Nova

Zelândia, Maya Hasegawa recorda:

Então, eu sei que nesse caso aqui, eu vou mencionar a rádio Vox Brasil. Ela não é uma rádio comunitária ela é uma Rádio Comercial e ela começou através de brasileiros, o Rodrigo que já estava aqui na Nova Zelândia, mas ele trabalhava com uma empresa de limpeza, ele tem a empresa dele e ele resolveu começar essa rádio porque na verdade ele queria trazer para cá ele tem um cunhado que estava nos Estados Unidos, a pessoa que levou a primeira [retransmissora da rádio] Transamérica para o exterior. Então a primeira subsidiária ou retransmissão da Transamérica no exterior é feito pelo Eduardo Meirelles que é o Eddie e não vamos começar a fazer um projeto semelhante aqui na Nova Zelândia e aí foi assim que ele trouxe o Eddie para a Nova Zelândia ele começaram a rádio Vox Brasil; ele era aquele que fazia também de tudo e infelizmente por algumas dissidências, brasileiro, aquela famosa história: é barraqueira mesmo, a gente não tem, o Sangue Quente. Eles tiveram uma dissidência, infelizmente, a rádio hoje é tocada pelo Rafael Albano e ele trabalhou um tempão na Band e ele era mais da por trás das câmeras, tanto é que, caso vocês tenham a possibilidade oportunidade de ouvir a entrevista que eu fiz com ele na Nova Zelândia sem falar inglês e assim cara e coragem no momento que eles estavam precisando de alguém para tocar o projeto é uma coisa assim que ir quando é para ser é não se realmente aquele que tá guardado para gente ir lá e aí nessa feliz coincidência o Rafa[el Albano] é especialista nessa área toda de mídias e começou a na rádio Vox Brasil. 
Além da equipe atuante em outras emissoras que retransmitem o programa Kia Ora

Brazil, Maya Hasegawa comenta aspectos determinantes na audiência do programa, com relação à captação de emissoras FM na Nova Zelândia em meio a uma limitação com relação os receptores de carro preparados para a banda FM do padrão japonês $(76-89 \mathrm{MHz})$ e o internacional (Europa e Estados Unidos), com recepção entre os 87 - 109MHz:

O Eddie vai ter um projeto sendo lançado por ele que não tem a ver com rádio Vox Brasil e neste caso a rádio Vox Brasil, por exemplo, por enquanto está só no aplicativo e rádio online; eles estão pleiteando uma banda FM também, mas ela é uma frequência cento e pouco (100-107 MHz) e não sei se você sabe, mas a maioria dos carros que tem aqui na Nova Zelândia são importados do Japão e a captação da rádio vem programada para carros japoneses. Não contempla mais do que $90.0 \mathrm{MHz}$; é uma tragédia, então se você quisesse ouvir uma rádio 101.5 MHz você não houve a menos que seja um carro que seja do sistema que não seja oridental e nos carros japoneses... Não pega! Olha que desgraça: nisso japonês não é o melhor... E aí o que o Eduardo está preparando uma rádio FM que vai pegar na banda desses carros japoneses inclusive, então acredito que o alcance vai ser maior, mas também vai ter o aplicativo e tudo mais. Ele também falou que vai continuar falando em português então programação vai ser 24 horas e 7 dias por semana, em português aqui na Nova Zelândia. E é uma felicidade gigante já que vai ter o programa meu e dele é o vamos ver com qual frequência a gente vai conseguir ter, mas enfim eu vou jogando em todas as redes sociais.

A produção dos programas ocorre em uma maneira diferente da habitual - ainda que a pessoa esteja formalmente vinculada com a emissora. Maya Hasegawa aborda como ocorre o processo de pós-produção na Free FM:

Eu digo teoricamente porque essa minha vida corrida, trabalho voluntário, infelizmente, por mais que eu ame a gente não consegue fazer todas as semanas e inclusive da semana passada. Hoje, se não me engano tem reprise. Ah... Nossa: a gente teve um programa novo e a gente, eu, digo - equipe, gravo, edito, divulgo, é pesado para uma pessoa só é muito pesada ainda mais porque quando a gente tem papo, os [convidados] que rendem pelo menos uma hora uma hora e meia a gente trabalhando com 28 minutos não é fácil, eu faço aqui essa observação: 58 para mim, só isso! Porque inicialmente eu tinha um programa que era de 58 minutos e ponho muito pesado, eu não estava aguentando. E aí que me deram essa oportunidade de mudar para 28 minutos, o meu programa é transmitido então, de forma inédita, estreia sempre há. E aí ele entra no aplicativo Max Radio no Spotify também na rádio Vox Brasil e retransmitido assim como na FM de 
Auckland, a rádio de outra colega brasileira. Esses são os únicos que me deram um sinal e tiveram interesse em retransmitir o programa e a gente fala com brasileiros e gringos ligados à comunidade brasileira do mundo todo e a gente se queixou na bastante: será que a rádio está chegando ao fim por mais que as pessoas falem que o podcast tá fazendo esse bolo e tem muita gente ouvindo mais podcast neste momento pelo menos na rádio Vox Brasil e têm falado também pela internet mostrando quase como se fosse uma TV é uma coisa eu queria ressaltar de como é pesado para gente fazer tudo isso by yourself.

Maya Hasegawa também aborda sobre como a mudança para a Nova Zelândia também impactou na área de atuação:

Então quando eu fui criar o programa aquele momento que você entra no estúdio Você tem o computador a sua disposição microfone na sua frente e ele fala assim pode falar o que você quiser é que der na telha, aí a gente não tem ideia do que falar... Eu não tinha experiência em rádio nenhuma. A minha formação, originalmente eu sou farmacêutica-bioquímica ainda na USP, colega de vocês, mas com 24 anos eu comecei a cantar. A minha carreira foi mais voltada como cantora e como atriz chego a fazer alguns papéis iguaiszinhos a locuções, mas não tinha experiência de rádio.

Apesar da liberdade de criação estar garantida, Hasegawa também explica que a abordagem de assuntos com temas sensíveis torna-se complexa porque:

Para alguns isso pode parecer fácil, mas não é então eu já não tinha mais ideia também do que falar de temas então eu comecei a migrar o formato do programa e ele estava como hoje assim a gente já conversou com pessoas a França, Estados Unidos, Inglaterra, Alemanha e para cada um, como eu posso fazer o programa tanto em espanhol e inglês em japonês em português se a gente quiser a gente faz essa variedade a gente mistura e de novo africano e me deu a carta branca e falado assim: você pode falar o que você quiser. A única ressalva que eu tive foi: no momento das eleições daqui eles falaram assim: você tem que saber quais são as regras do TRF o TSE daqui. Eles fizeram tudo a preparação da gente, o que a gente pode o que a gente não pode falar. Então que ele tinha um só pedido era que a gente não se posicionar-se em relação ao [um candidato], por exemplo: Qual o partido que é o melhor? E eu teria que deixar os convidados falar sem a opinião deles, de qual partido é melhor, porque e ele a gente não poderia de forma alguma ficar divulgando Fake News, etc. Então a gente teria que realmente pesquisar antes de sair colocando qualquer informação tanto é que eu tive algumas entrevistas falando um pouquinho das eleições e assim eu não poderia falar a minha opinião

\section{Revista ALTERJOR}

Grupo de Estudos Alterjor: Jornalismo Popular e Alternativo (ECA-USP)

Ano 12 - Volume 01 - Edição 25 - Janeiro-Junho de 2022 
nem dos referendos que a gente votou, se as pessoas votariam sim ou não para maconha e também para a morte assistida e eu não sei se vocês teriam interesse em ter votado em tudo isso. Mas a galera aqui ficou em polvorosa em relação à maconha. Eu que trabalho como farmacêutica bioquímica no laboratório de análises inclusive é analisando maconha, mas não fumando, tá gente, não é toda a pressão e eu vi que uma galera tava preparando produtos que seriam para uso recreativo e infelizmente com esse não que eles receberam um referendo e muita coisa foi por água abaixo.

A Nova Zelândia tem uma identidade multicultural não só pelo idioma maori, mas com a sign language - linguagem de sinais, não só utilizada por surdos-mudos, mas com um estatuto de idioma. Além dos três idiomas: inglês, maori e de sinais, Maya Hasegawa explica como os contrastes ocorrem:

Hoje em dia com a Internet você tem acesso a tudo isso, é muito fácil. Se você quiser, tem vários aplicativos que você entra só para falar com pessoas é voluntário você pode aprender inglês é fácil acesso. Não é uma desculpa para você não aprender inglês mais uma vez que você sai do Brasil aí você vem aqui na Nova Zelândia, que é uma ilha, mas são duas ilhas. Mas enfim é um local remoto se você não tem essa diversidade cultural tão grande quanto é na Europa. Quanto é nos Estados Unidos ou como é no Brasil só que o Brasil a gente não percebe tanto. Depende das áreas da região que são mais remotas que realmente você não tem acesso a imigrantes, mas aqui na Nova Zelândia a senha é o local que eu mais vi quinze por cento há quase trinta por cento eles são pelo menos imigrantes é uma população gigante de imigrantes eu nunca tinha visto tanto malasiano na minha vida, filipino, cantor indiano e tantas outras coisas que eu vejo aqui pela primeira vez na minha vida. É muito interessante de ver e todas essas pessoas você venda na rua e elas falam o idioma delas é, mas por outro lado, a gente também tem é aguçado por causa do convívio. Xenofobia, a gente viu isso eu tive várias pessoas que, sei lá, um babaca para o carro do lado do meu para abrir o vidro, eu achei que ele ia falar se o pneu está furado e o cara grita: volta para sua casa volta para seu país. Eu vi isso eu só xingando assim na rua então é tem essa questão tem esse lado, mas que na programação a gente vê que as pessoas tentam incentivar ou manter os brasileiros - caso vocês ainda não tenham visto a gente tem uma festa uma associação uma entidade chamada Brasileirinhos.

A questão do idioma de minorias também apresenta nuances quanto à abordagem e os espaços de fala. Maya Hasegawa comenta sobre o caso de brasileiros na Nova Zelândia:

Ah e eles tentam levar o manter o idioma português para as criancinhas então eles começam com o playback. O governo já 
reconheceu esse play deles, que basicamente são brincadeiras pedagógicas como idioma em português então vai ter uma professora que toca um violão que vai fazer o competir com marionetes, vai brincar com a criançada com brincadeiras brasileiras vai fazer se ela celebração de festa junina tudo mais tudo para incentivar o idioma português. Infelizmente esse projeto lindo é só em óculos na ilha Sul, onde a gente tem muitos brasileiros em questão. Parece que um terço da população da cidade de Cristchurch é de brasileiros, é uma quantidade muito grande. Você vai ao supermercado a você vai comprar carne você tem aí que tá escrito Picanha Brasileira, entendem que se leva picanha, apesar de você conhecer bem o corte de uma picanha de verdade.

Com relação ao que mais motiva a atuação no rádio, Maya Hasegawa comenta que:

Muitas comunidades do Brasil e a gente vê é a necessidade da população daquele grupo em que eu estou inserida, por exemplo, até um tempo atrás a gente tinha uma brasileira chamada Juliana ainda sem visto, mas ela é uma cadeirante, tem lupus de acordo com a lei de imigração da Nova Zelândia uma pessoa com algumas doenças crônicas ela não tem direito ao visto de residência o e durante a pandemia ela teria o seu visto cancelado isso porque ela já está há mais de 15 anos na Nova Zelândia morando com a sua família né ela tinha pedido antes o visto então eles deram o visto para ela como temporário ela trabalha ela tem um salário altíssimo quem é que ganha se ela mais do que 38 dólares a hora e o salário mínimo daqui da Nova Zelândia são as que [remuneram NZD] 17 e alguma coisa por hora; ela pega 38 horas então não é um salário meia-boca, aquela qualificada tem que ter pós-graduação de lá, tem cara bom mas, mesmo ela contribuindo pagando imposto desse jeito a Nova Zelândia ia mandar embora e eu através da Rádio eu consegui fazer uma campanha em que a gente coletou trocentas [centenas de] assinaturas no abaixo-assinado para que ela ficasse na Nova Zelândia a partir do momento que eu vi o quanto o meu trabalho conseguiu ajudar esta moça e ela conseguiu a residência acho que isso me motivou muito e mais muito então eu acho aqui essa questão lógica como eu falei a rádio comunitária no Brasil também tem para fazer esse tipo de coisa de promover e ajudar a fazer campanha para a comunidade local mas aqui na Nova Zelândia você vê que o governo incentiva e ajuda, ainda mais agora nesse momento da pandemia que ele chegar e falar que vocês precisam de ajuda da Cruz Vermelha,etc. Façam, divulguem nas rádios, é esse momento que eles vêm cobrando da gente assim a sua comunidade sabe que eu tenho que fazer então tem eleição você falou para sua comunidade como funciona a eleição. Quais são os prazos, etc. Bom, então o governo quer que também a gente ajude a divulgar e seja utilidade pública no nosso idioma.

Com relação a outro momento emocionante, Maya Hasegawa recorda que:

Revista ALTERJOR

Grupo de Estudos Alterjor: Jornalismo Popular e Alternativo (ECA-USP)

Ano 12 - Volume 01 - Edição 25 - Janeiro-Junho de 2022 
20 mil visualizações aqui, um número significativo para mim muito significativo e a gente vai como as pessoas têm esse carinho como as pessoas torceram por ela, as pessoas queriam que ela ficasse ela tiver sucesso porque afinal de contas isso abre um precedente também para outras pessoas se vocês derem uma olhada nas leis de imigração da Nova Zelândia pessoas que têm diabetes e outras doenças crônicas talvez eventualmente não consiga o visto de residência. Então uma coisa que a Juliana falou assim: Maya uma pessoa que não me deixa parar com essa minha luta é, por exemplo, a o pai de uma menininha que também tem uma doença, ela não quis falar muito dessa a doença ou da criança e ela falou assim o pai veio chorando para mim falando: por favor, vença essa batalha por nós é porque eu não quero que a minha filha saiba que a gente não pode ficar na Nova Zelândia por causa dela... Eu fiquei emocionada fazer lembrar porque assim começam as aulas vocês vão país que um abraço todo mundo que seja pró-vida e bla bla blá nesse momento de proteger os bens a cidadão deles eles somente protegem mas nós que somos imigrantes.

Você vê é muita gente está indo embora porque não conseguem renovar o visto. O clamor desse pai falando assim dois com essa batalha por mim pela minha filha porque eu não posso ir ao público dizer que eu estou batalhando por isso porque assim a minha filha não conseguiu visto, eu tenho que ir embora. Em uma dessas, num dos voos, a gente tem um voo de repatriação então o voo pago pelo governo brasileiro e o seguinte que foi pago metade pelo governo chileno e nele a gente viu uma família embora com a criança autista porque o governo, enfim, falou: tchau a gente não vai te dar o visto a gente não vai te ajudar, um outro público completamente diferente. Não só da Nova Zelândia, mas correndo para gente tem o caso da Ana que bombou nas mídias sociais, caso vocês ainda não tenham visto, mas é uma violinista que começou no Projeto Guri em Osasco e aí ela foi para o mundo ela foi com a Bulgária também uma bolsa lá e sem falar búlgaro não conseguiu ganhar o mundo então a gente vê também que pelo que hora Brasil a gente conseguiu um pouco mais de seguidores porque de acordo com a Austrália ela pediu o visto de artista Internacional e aí a Austrália falou assim: você só vai conseguir esse visto se você tiver muitos seguidores você tem que ser uma influenciadora significativa, na mídia, e ela tinha o que falar com 10.020 mil seguidores, de um dia para o outro por causa dessa campanha que a gente fez, inclusive, até o Luciano Huck ajudou, a Família Lima ajudou tudo mais. E a gente fez um pequeno pedacinho aqui na nossa comunidade ela passou de mais de meio milhão de seguidores. E então acredito que em breve esperamos o governo australiano conceder o visto para ela de artista internacional, mas é muito lindo de ver a história dela também se vocês puderem ouvir a entrevista, é uma outra entrevista que a gente fez, tem situações como eu falei o governo neozelandês não deixar depois do lockdown ele não deixou pessoas com residência voltarem para Nova Zelândia e, salvo exceções raras, vem um aí: eu sou médico que está trabalhando lá no combate à COVID. Então você pode voltar, o resto muito obrigada,

\section{Revista ALTERJOR}




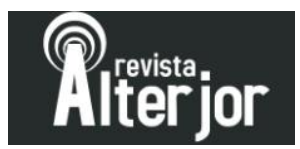

fica uma próximo, a gente não quer você não foi um jeito que eles encontraram de dar uma limpa.

Embora o pedido de visto se aplique para trabalhadores residentes, a documentação não se torna multilateral, mesmo quando pessoas da mesma família irão residir na mesma residência, os portadores de doenças têm restrições maiores. Maya explica como isso ocorre:

A situação de muitos brasileiros é um caso de um, que a gente saiba, se a família saiu no voo de repatriação, então eu passo ação porque naquele momento do olho do furacão da pandemia só para vocês terem uma noção um voo uma perna Brasil Nova Zelândia Nova Zelândia Brasil estava custando mais de 10 mil reais para uma pessoa, isso não é dinheiro pela internet, não tem sobrado nada compra de cinco passagens para hoje enfim e aí as pessoas ficaram desesperadas porque muita gente teve que sair correndo: eles cancelaram os vistos das pessoas muitos vistos e expiraram [outros], muita gente não sabia o que fazer e realmente foi para as ruas e nesse momento eu tive oportunidade de conversar com a dona Karina que é uma brasileira que mora em Queenstown que ela mandou as regiões mais afetadas aqui na Nova Zelândia não só pelos brasileiros, mas todos os imigrantes porque eles são tem economia baseada em turismo não sei se você sabe mais de $72 \%$, se não me engano do, do PIB da Nova Zelândia é oriundo de turismo. Então tá sofrendo para caramba a economia da Nova Zelândia a região em que eu moro, a agricultura é a principal fonte então já que eu estou mesmo, lá se foi a região de Waikato é uma vez que estão tocando a Nova Zelândia inteira neste momento, com a indústria de laticínios de agricultura e tudo mais mas por isso eu não vejo tanta gente aqui passando necessidade.

Em meio ao fechamento de postos de trabalho na ilha norte, a situação econômica de um país que depende do turismo em plena pandemia de COVID 19 gerou outros impactos. Maya Hasegawa pondera:

Mas lá no Sul, em Queenstown, nas ilhas turísticas a coisa ficou feia; E aí eu tive para gente conversar com Alana Karina que ela tocou todo o projeto e na hora que eles precisam a gente teve esse bando de brasileiro que estavam ficando desempregados em casa sem comida sem nada e o consulado embaixada infelizmente não levantou a bunda lá de Wellington, a capital, para ir lá à região cuidar e ajudar os brasileiros eles ficaram lá remotamente assim: ah, beleza... E aí brasileiros estão com problema lá então eu estou vendo lá com o Brasil que a gente pode fazer aí. Foi aí que a comunidade brasileira se fortaleceu pelo menos nesse momento.

\section{Revista ALTERJOR}

Grupo de Estudos Alterjor: Jornalismo Popular e Alternativo (ECA-USP)

Ano 12 - Volume 01 - Edição 25 - Janeiro-Junho de 2022 


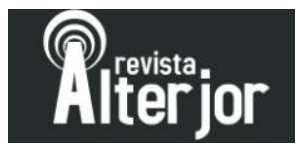

A questão de não se saber qual brasileiro chegou ou saiu da Nova Zelândia não se restringe somente a questões particulares ou ao consulado brasileiro. A utilização de redes sociais em plena era da informação e visibilidade digital revela personagens invisíveis. Maya Hasegawa comenta:

Tem muitos brasileiros que vem para cá que não estão nas mídias sociais e eles não se interessam eles não querem saber ele chegou à cidade, não tem brasileiro aqui eu não vejo ninguém falar português não tem brasileiro aí, puxa vida meu filho, minha filhinha, não tem com quem brincar em português porque não tem nenhum brasileiro! Ou seja, as pessoas realmente estão avessas e fora das mídias sociais e são exatamente essas pessoas que precisaram saber da gente quando tinha voo de repatriação e infelizmente como a Embaixada que tem todos os dados e sabem onde cada brasileira está, mas não deu mais informações na hora, se tem voo hoje repatriação quase metade do voo veio vazio foi, mas não foi é porque é muita gente nem soube que o voo existiu, mas que se soubesse teria voltado para o Brasil. Daí a gente vê pessoas fantásticas se mobilizando nas mídias sociais e eu fui cobrindo essas regiões com as entrevistas para saber como é que as pessoas estavam se virando e como é que a gente poderia ajudar nessa situação foi muito interessante de ver, mas de um lado triste de um lado feliz, porque feliz como a gente vê as pessoas conseguindo voltar para o Brasil em segurança e triste porque a gente vai vendo a cidade esvaziando muitos amigos indo embora.

\section{Considerações finais}

A integração multicultural possui aspectos desafiadores e torna-se ao mesmo tempo necessária e complexa. O caso da Nova Zelândia possuir leis em rumo à diversidade cultural, como a transmissão de programas de rádio em idiomas diferentes dos oficiais inglês e maori.

A questão cultural do aspecto multifacetado torna-se evidente quando os projetos de implantação de políticas públicas encontram como resistência a afirmação "fácil resolver problemas pequenos, mas não num país enorme como o Brasil" - porque a resolução de problemas acarreta no reconhecimento da dificuldade. De forma singular, a entrevistada Maya Hasegawa revelou a existência de problemas burocráticos, de xenofobia e negligência em situações definidas pelo apoio da comunidade tornou-se essencial na superação de cada caso apresentado, mesmo num país pequeno, do tamanho do Estado do Espírito Santo.

\section{Revista ALTERJOR}

Grupo de Estudos Alterjor: Jornalismo Popular e Alternativo (ECA-USP)

Ano 12 - Volume 01 - Edição 25 - Janeiro-Junho de 2022 


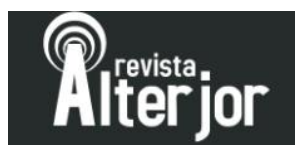

O rádio comunitário da Nova Zelândia - nesse caso, do programa Kia Ora Brazil - se tornou um importante canal de informação e integração, cuja principal mensagem demanda uma necessidade de aprendizado multicultural e do fortalecimento dos laços da comunidade.

\section{Referências}

CEBRIÁN HERREROS, Mariano. La rádio en internet. Buenos Aires: La Crujía, 2008.

HALL, STUART. Da diáspora: identidades e mediações culturais. Belo Horizonte: UFMG, 2003.

HOWE, Jeff. O poder das multidões: porque a força do coletivo está remodelando o futuro dos negócios. Rio de Janeiro: Elsevier, 2009.

\section{Websites}

COMMUNITY ACCESS MEDIA. Access Media. Disponível em:

https://www.accessradio.org/

FREE FM. Kia Ora Brazil. Disponível em:

https://www.freefm.org.nz/Programmes/Details.aspx?PID=bb07de6b-0704-436c-945f-

8074af262876

NEW ZEALAND. Māori Language Act 1987. Disponível em:

http://www.legislation.govt.nz/act/public/1987/0176/latest/DLM124116.html

NEW ZEALAND. Broadcasting Act 1989. Version as at October 28, 2021. Disponível em: https://www.legislation.govt.nz/act/public/1989/0025/latest/whole.html\#DLM158011

NEW ZEALAND. Before you travel to New Zealand. Disponível em: https://www.immigration.govt.nz/new-zealand-visas/apply-for-a-visa/tools-andinformation/your-journey-to-new-zealand/before-you-travel-to-new-zealand

NZ ON AIR. Diversity Report 2020. Disponível em:

https://www.nzonair.govt.nz/research/diversity-report-2020/

NZ ON AIR. Community Access Radio. Disponível em: https://www.nzonair.govt.nz/about/our-funding-strategy/community-accessradio/? fbclid=IwAR29EdJ7p6-g38zu5fi4rzsJX0CV6jhjwTgaFIbnoT2-Ayn6cklaQwBSCEs

NEW ZEALAND COMMUNITY ACCESS MEDIA ALLIANCE. What is Access

Media. Disponível em: http://www.cama.nz/

RADIO VOX BRAZIL. Disponível em: https://radiovoxbrazil.com/

\section{Documento sonoro (entrevista)}

HASEGAWA, Maya. Entrevista: Maya Hasegawa [set. 2020]. Entrevistador: Carlos Augusto Tavares Junior. São Paulo: ECA-USP, 2020. 1 arquivo. WAV (177,4 min.).

\footnotetext{
Revista ALTERJOR

Grupo de Estudos Alterjor: Jornalismo Popular e Alternativo (ECA-USP)

Ano 12 - Volume 01 - Edição 25 - Janeiro-Junho de 2022

Av. Professor Lúcio Martins Rodrigues, 443, Cidade Universitária, São Paulo, CEP: 05508-020
} 